\title{
THE MOMENT OF MAXIMUM NORMED SUMS OF RANDOMLY WEIGHTED PAIRWISE NQD SEQUENCES
}

\author{
DONG ZhaO, XiaOQIN Li AND KeHAN Wu
}

\begin{abstract}
This paper investigates the moment of maximum normed sums of randomly weighted pairwise negative quadrant dependent (NQD) random variables. A sufficient condition to the moment of this stochastic process is obtained, which extends the existing results.
\end{abstract}

Mathematics subject classification (2010): 60F15, 60F 25 .

Keywords and phrases: Pairwise NQD sequences, randomly weighted, maximum normed.

\section{REFERENCES}

[1] A. AdLER, A. RosALSKy, Some general strong laws for weighted sums of stochastically dominated random variables, Stoch. Anal. Appl. 5 (1987), 1-16.

[2] A. AdLER, A. Ros ALS KY, R. L. TAYLOR, Strong laws of large numbers for weighted sums of random elements in normed linear spaces, Int. J. Math. Math. Sci. 12 (1989), 507-530.

[3] P. Y. Chen, S. X. Gan, On moments of the maximum of normed partial sums of $\rho$-mixing random variables, Statist. Probab. Lett. 78 (2008), 1215-1221.

[4] P. Y. Chen, S. H. Sung, Generalized Marcinkiewicz-Zygmund type inequalities for random variables and applications, J. Math. Inequal. 10 (2016), 837-848.

[5] P. Y. CHEN, S. H. SUNG, A Bernstein type inequality for NOD random variables and applications, J. Math. Inequal. 11 (2017), 455-467.

[6] X. Deng, X. J. WAng, Y. Wu, Y. Ding, Complete moment convergence and complete convergence for weighted sums of NSD random variables, RACSAM 110 (2016), 97-120.

[7] X. Deng, X. J. WANG, F. X. XIA, Hajek-Renyi-type inequality and strong law of large numbers for END sequences, Comm. Statist. Theory Methods 46 (2017), 672-682.

[8] S. X. GAN, P. Y. CHEN, Some limit theorems for sequences of pairwise NQD random variables, Acta. Math. Sci. Ser B Engl. 28 (2008), 269-281.

[9] D. L. HANSON, F. T. Wright, A bound on tail probabilities for quadratic forms in independent random variables, Ann. Math. Statist. 42 (1971), 1079-1083.

[10] T.-C. Hu, C. Y. ChiAnG, R. L. TAYLOR, On complete convergence for arrays of rowwise mnegatively associated random variables, Nonlinear Anal. 71 (2009), e1075-e1081.

[11] K. Joag-Dev, F. Proschan, Negative association of random variables with applications, Ann. Statist. 11 (1983), 286-295.

[12] M. H. Ko, Complete convergences for arrays of row-wise PNQD random variables, Stoch.: Int. J. Probab. Stoch. Process. 85 (2013), 172-180.

[13] E. L. Lehmann, Some concepts of dependence, Ann. Math. Statist. 37 (1966), 1137-1153.

[14] X. Q. LI, Z. R. ZhaO, W. Z. YAnG, S. H. HU, The inequalities of randomly weighted sums of pairwise NQD sequences and its application to limit theory, J. Math. Inequal. 11 (2017), 323-334.

[15] P. Matula, A note on the almost sure convergence of sums of negatively dependent random variables, Stat. Probab. Lett. 15 (1992), 209-213.

[16] A. T. Shen, Y. ZhAng, A. Volodin, On the strong convergence and complete convergence for pairwise NQD random variables, Abstr. Appl. Anal. 2014 (2014), Article ID 893906, 7 pages.

[17] S. H. SUNG, Strong limit theorems for Pairwise NQD random variables, Comm. Statist. Theory Methods 42 (2013), 3965-3973. 
[18] S. H. SUNG, Convergence in $r$-mean of weighted sums of NQD random variables, Appl. Math. Lett. 26 (2013), 18-24.

[19] X. J. WAng, X. Deng, L. L. Zheng, S. H. Hu, Complete convergence for arrays of rowwise negatively superadditive-dependent random variables and its applications, Statistics, 48 (2014), 834850.

[20] X. J. Wang, T.-C. Hu, A. Volodin, S. H. Hu, Complete convergence for weighted sums and arrays of rowwise extended negatively dependent random variables, Comm. Statist. Theory Methods 42 (2013), 2391-2401.

[21] X. J. WANG, L. X. LI, S. H. Hu, X. H. WANG, On complete convergence for an extended negatively dependent sequence, Comm. Statist. Theory Methods 43 (2014), 2923-2937.

[22] X. J. WANG, C. XU, T.-C. Hu, A. Volodin, S. H. Hu, On complete convergence for widely orthant-dependent random variables and its applications in nonparametric regression models, Test $\mathbf{2 3}$ (2014), 607-629.

[23] Y. B. WANG, J. G. YAN, F. Y. ChenG, X. Z. CAI, On the strong stability for Jamison type weighted product sums of pairwise NQD series with different distribution, Chin. Ann. Math. 22A (2011), 701706.

[24] F. T. WRIGHT, A bound on tail probabilities for quadratic forms in independent random variables whose distributions are not necessarily symmetric, Ann. Probab. 1 (1973), 1068-1070.

[25] Q. Y. WU, Convergence properties of pairwise NQD random sequences, Acta Math. Sin. Chin. Ser. 45 (2002), 617-624.

[26] Q. Y. WU, Complete convergence for negatively dependent sequences of random variables, J. Inequal. Appl. 2010 (2010), Article ID 507293, 10 pages.

[27] Q. Y. WU, Almost sure central limit theorem for self-normalized products of partial sums of negatively associated sequences, Comm. Statist. Theory Methods 46 (2017), 2593-2606.

[28] Q. Y. WU, Y. Y. JIANG, The strong law of large numbers for pairwise NQD random variables, J. Syst. Sci. Complex. 24 (2011), 347-357.

[29] Y. F. WU, G. J. SHEN, On convergence for sequences of pairwise negatively quadrant dependent random variables, Appl. Math. 59 (2014), 473-487.

[30] Y. F. WU, M. L. GUO, Convergence of weighted sums for sequences of pairwise NQD random variables, Comm. Statist. Theory Methods, 45 (2016), 5977-5989.

[31] C. XU, M. M. XI, X. J. WANG, H. XIA, $L_{r}$ convergence for weighted sums of extended negatively dependent random variables, J. Math. Inequal. 10 (2016), 1157-1167.

[32] W. G. YANG, D. Y. ZHU, R. GAO, Almost everywhere convergence for sequences of pairwise NQD random variables, Comm. Statist. Theory Methods, 46 (2017), 2494-2505.

[33] W. Z. YANG, S. H. Hu, Complete moment convergence of pairwise NQD random variables, Stoch.: Int. J. Probab. Stoch. Process. 87 (2015), 199-208.

[34] M. YAO, L. LIN, The moment of maximum normed randomly weighted sums of martingale differences, J. Inequal. Appl. 2015, 2015:264. 